\title{
Entre um tijolo e um lance de dados: sobre o escrever e escrever teses, instituições e obras de arte
}

Between a bric and un coup de dés: on writing and writing theses, institutions and art works

Mônica Hoff Gonçalves ${ }^{1}$ 


\section{Resumo}

A partir de análise da tese $\mathrm{Mu}$ seu de Arte Moderna Departamento das Águias, defendida por Keila Kern na ECA/ USP em 2015, o presente artigo busca refletir sobre o processo de escrever, fazer arte um trabalho de arte e escrever uma tese como práticas igualmente irregulares e poéticas - escrever como um lance de dados, tal qual defendia Mallarmé; escrever para tornarmo-nos selvagens, como argumentara Marguerite Duras.

Palavras-chave: pesquisa em arte escrever - metodologia - artes visuais

\section{Abstract}

Having the thesis Museum of Modern Art Department of Eagles, held by Keila Kern at ECA / USP in 2015, as a starting point, this article seeks to reflect on the process of writing, make an art work and write a thesis as practices also irregular and poetic - writing as un coup de dés, as it defended Mallarmé; write to make ourselves wild, as argued Marguerite Duras.

Keywords: research in art - writing methodology - visual arts

ISSN: 2175-2346

${ }^{1}$ Artista, curadora e pesquisadora. Doutoranda em Processos Artísticos Contemporâneos no PPGAV/UDESC. Brasil. monicahoff@gmail.com 
La fiction affleurera et se dissipera, vite, d'après la mobilité de l'écrit. Mallarmé

A construção de um texto é um caminho de muitas mãos. Mais do que organizar palavras, pontuar frases, criar ritmo, construir um texto é (d)obrar ideias, conceitos, crenças e apostas. É criar um outro universo para as coisas que já existem e para as que ainda estão por vir. É fazer um pacto com a invenção e um tratado com o desassossego. É, sobremaneira, criar uma alegoria - de algo que acreditamos saber, mas que transposto a outro meio demonstra, muitas vezes, saber mais do que nós. Escrever é transformar barro em tijolos e tijolos em casas $^{1}$ e, ao mesmo tempo, um indomável lance de dados².

Em Marcel Broodthaers - Museu de Arte Moderna Departamento das Águias ${ }^{3}$, tese de doutorado de Keila Kern 4 , a autora parece evidenciar isto na máxima potência ao colocar-se no exercício de reconstituir a história do referido museu ${ }^{5}$, criado em 1968 pelo artista belga, a partir de imagens presentes em publicações sobre o assunto, também pareceres e leituras dos principais interlocutores do artista, bem como do legado literário do próprio artista. Assim, ao sistematizar uma possibilidade de arquivo (em português) para o Museu, ela o reinventa. O detalhe é que este museu é um museu fictício, criado por Broodthaers como uma espécie de paródia política ao mundo da arte e das exposições.

Deste modo, a reinvenção feita por Keila ganha dupla tonalidade, ela traduz e sistematiza registros imprecisos de um museu imaginário. Ela o inventa em sua narração.

O Musée d'Art Moderne Département des Aigles, como proposta, era ainda que fictício, ao mesmo tempo instituição e obra de arte, sistema e objeto, portanto um trabalho complexo em que os códigos da arte, e principalmente do mundo da arte, eram colocados em cheque. Diante disso, Keila poderia ter proposto uma análise histórica ou uma abordagem teórica do museu de Broodthaers, no entanto, a pesquisadora localiza sua pesquisa no campo das poéticas visuais e faz da tradução e da escrita literária, e também da própria tese, um objeto de criação. De alguma maneira, poderíamos dizer que ela reescreve o museu, sem que ele jamais tenha sido escrito; ela propõe uma espécie de exercício ekphrático ${ }^{6}$ - descreve um trabalho de arte (ou visual) cuja existência é imprecisa, portanto, ao fazê-lo, o inventa e reinventa ao mesmo tempo.

Não por acaso, Keila abre sua tese com o poema Un Coup de Dês, de Mallarmé.

\footnotetext{
1 Reflexão de Maria Ester de Freitas sobre a produção intelectual e prática da escrita. Ver FREITAS. Maria Ester. Viver a tese é preciso! In: A bússola do escrever: desafios e estratégias na orientação e escrita de teses e dissertações. BIANCHETTI, Lucídio e MACHADO, Ana Maria Netto. (Org.) São Paulo: Cortez, 2012. p. 220.

2 Alusão ao poema Un Coup de Dês, de Mallarmé, no qual o poeta francês inaugura a presença do espaço gráfico (suporte) como campo de força para o poema, sendo este ato desde já um lance de dados. Ver CAMPOS, Augusto; CAMPOS, Haroldo e PIGNATARI, Décio. Mallarmé. São Paulo: Perspectiva, 1991, p. 149173.

${ }^{3}$ Ver KERN, Keila. Marcel Broodthaers - Museu de Arte Moderna Departamento das Águias. Tese de doutorado. ECA/USP, 2015. Disponível em <http://www. teses.usp.br/teses/disponiveis/27/27159/tde-16102014-094023/pt-br.php> Acesso em 22/04/2016

4 Keila Kern é pesquisadora, curadora e professora do ensino superior na Escola de Música e Belas Artes do Paraná (EMBAP) em Curitiba. Graduada em Pintura pela EMBAP (1992). Especialista em História da Arte - Escola Música e Belas Artes do Paraná (1994). Mestre em Poéticas Visuais(2008) e Doutora em Poéticas Visuais (2015) pela Escola de Comunicação e Artes (ECA) - Universidade de São Paulo (USP).

${ }^{5}$ Nas palavras de Marcel Broodthaers, o Museu de Arte Moderna Departamento das Águias é "um museu fictício. Ele faz, por um lado, uma paródia política com relação aos eventos de arte, e por outro lado, uma paródia artística com relação aos eventos políticos. Que é o que de fato fazem museus oficiais e eventos como a documenta de Kassel. Com a diferença, no entanto, de que uma obra de fiç̧ão permite capturar e, ao mesmo tempo, esconder esta realidade". Ver Marcel Broodthaers, Musée d'Art Moderne, Département des Aigles, Section Art Moderne et Publicité (1972), in SNAUWAERT, Dirk. Marcel Broodthaers. Musée d'Art Moderne, Département des Aigles, Section des Figures, 1972. The artist as curator. MOUSSE 46 Issue \#5.

6 Ekphrasis, do grego ek phrasis, respectivamente, "fora" e "falar", consiste em descrever literariamente uma obra de arte.
} 
O que poderia em outras circunstâncias ser apenas um prefácio introdutório de um trabalho científico se mostra, em Museu de Arte Moderna Departamento das Águias, como parte integrante do próprio trabalho. Todo pensamento emite um lance de da$\operatorname{dos}^{7}$, afirmara o poeta francês ao final de seu poema. Na tese de Kern, tal qual um prefácio, o fim do poema de Mallarmé é o início de sua escrita. E dadas as características de seu objeto de estudo, a presença do poema conforma-se como uma inserção sua na história do Museu de Arte Moderna Departamento das Águias, de Marcel Broodthaers. Impossível ver/ler o Museu de Arte Moderna Departamento das Águias a partir de hoje sem considerar Un Coup de Dês.

Escrever é, portanto, mais uma vez, fazer um pacto com a invenção e um tratado com o desassossego. É criar uma tese sobre algo, um algo que mais do que uma boa ideia, é na essência uma boa pergunta ${ }^{8}$. É, talvez, desconfiar com destreza e ter habilidade suficiente para fazer novas perguntas ao que se busca responder. Escrever tornanos selvagens ${ }^{9}$, afirmaria Marguerite Duras sobre o ato de escrever. Ao comentar que a escrita nos torna selvagens, Duras está também dizendo que "é preciso sermos mais fortes que nós para abordar a escrita, é preciso ser-se mais forte do que aquilo que se escreve"10. De alguma maneira, a tese de Keila Kern nos coloca diante desta força diante do objeto de estudo, a ponto de subverte-lo para seu próprio bem, sua própria sobrevivência. Kern profana seu objeto de estudo, e ao fazê-lo o respeita mais que tudo.

Sobre o risco que se corre quando nos entregamos à escrita e ao seu exercício incansável a ponto de fazer do texto, ou da tese, algo que não prevíamos, deixando-nos levar pelo que o ato da escrita escreve em nós, nos lembra Marguerite Duras: escrever ao lado do que precede o escrito é sempre estragá-lo. E, todavia, é preciso aceitar isso: estragar o malogro é regressar a um outro livro, a um outro possível desse mesmo livro ${ }^{11}$.

Em Um lance de dados, o poeta francês usa o espaço do poema como espaço de criação em tempo real. Mallarmé se vale do espaço gráfico como um campo de força para o poema. Para além da retórica exposta, ou da (des)forma proposta, o sentido do texto existe no estreito, porém prolífico, espaço de interação dos dois. É como se as palavras pautassem o espaço que, transformado, atribui novo sentido às palavras as quais, atualizadas, alteram o espaço mais uma vez. É como se um traduzisse o outro em movimentos incessantes criando uma zona de infindável transdução ${ }^{12}$, ou seja, de transformação.

O mesmo acontece no trabalho de Keila - a sistematização dos arquivos, registros, histórias, anedotas, imagens do Museu de Arte Moderna Departamento das Águias altera não apenas a percepção que possamos ter do museu de Broodthaers, mas o próprio museu. É como se a autora, ao reorganizá-lo (recurá-lo?) o instituísse novamen-

\footnotetext{
7 Ver KERN, Keila. Marcel Broodthaers - Museu de Arte Moderna Departamento das Águias. Tese de doutorado. ECA/USP, 2015. Prefácio. E também: CAMPOS, Augusto; CAMPOS, Haroldo e PIGNATARI, Décio. Mallarmé. São Paulo: Perspectiva, 1991, p. 149-173.

8 Ver Maria Ester de Freitas sobre o que é uma tese. Ver FREITAS. Maria Ester. Viver a tese é preciso! In: A bússola do escrever: desafios e estratégias na orientação e escrita de teses e dissertações. BIANCHETTI, Lucídio e MACHADO, Ana Maria Netto. (Org.) São Paulo: Cortez, 2012. p. 220.

9 Ver DURAS, Marguerite. Escrever. Trad. de Rubens Figueredo. São Paulo: Ed. Rocco. (1993;1994), p. 24.

10 Ibidem.

11 Ver DURAS, Marguerite. Escrever. Trad. de Rubens Figueredo. São Paulo: Ed. Rocco. (1993;1994), p. 30.

12 Transdução é o processo pelo qual uma energia se transforma em outra de natureza diferente, no entanto, esta transformação se dá na mediação entre indivíduos/corpos/objetos que estão em rede/relação não apenas entre si, mas com outros códigos e universos. Gilbert Simondon, filósofo francês abordar a ideia de transdução no livro El modo de existencia de los objectos tecnicos. Buenos Aires, Prometeo, 2007.
} 
te. Talvez, inclusive, seja exatamente isto que nos propõe Keila a ver a sistematização como uma curadoria e esta curadoria como um processo de criação, ou ainda a ver a tradução como uma boa traição, uma traição que liberta o que ainda não se sabia que havia ali.

Em um determinado momento de Un Coup de Dês, Mallarmé dispara: Sem presumir do futuro, o que sairá daqui, nada ou quase uma arte ${ }^{13}$. Nada ou quase uma arte é o que propõe Marcel Broodthaers com seu museu-obra e também o que enuncia Keila Kern com sua tese de invenção. No entanto, se Mallarmé e Broodthaers lançam os dados uma única vez, Keila reinventa as referências por eles criados numa nova possibilidade de leitura do Museu ao mesmo tempo em que acrescenta a tal leitura sua percepção, seu ritmo, sua maneira de dobrar memórias, conceitos, histórias, registros. Keila, muito engenhosamente caminha simultaneamente nos campos da prática artística e curatorial, da pesquisa histórica e da mediação/educação, uma vez que sua tese não analisa um conceito ou uma obra de arte, mas um sistema, ou uma instituição criada por um artista como uma obra de arte.

Keila traduz não para trair, mas para aprender. Porém um não está descolado do outro, para aprender é preciso trair, refutar e experimentar as coisas profundamente e desde outro lugar ou ângulo. É necessário atuar em paralaxe, movimentar-se diante do objeto. Como museu o Museu de Arte Moderna Departamento das Águias é uma excelente tese - uma provocação que não pretende responder, senão gerar ainda mais questionamentos; como tese, sem dúvida, ele é um bom convite a pensarmos sobre a maneira como produzimos conhecimento e como o legitimamos, sobre o que é científico e o que pode transformar a ciência.

Não sei o que é uma obra de arte, tampouco um museu, ou uma tese. Ninguém de fato o sabe. Mas, sem dúvida, sabemos quando encontramos um ${ }^{14}$.

Agora em português!

\section{Referências}

ALVES-MAZZOTTI, Alda Judith. In: A bússola do escrever: desafios e estratégias na orientação e escrita de teses e dissertações. BIANCHETTI, Lucídio e MACHADO, Ana Maria Netto. (Org.) São Paulo: Cortez, 2012. p. 25-44.

CAMPOS, Augusto; CAMPOS, Haroldo e PIGNATARI, Décio. Mallarmé. São Paulo: Perspectiva, 1991.

DURAS, Marguerite. Escrever. Trad. de Rubens Figueredo. São Paulo: Ed. Rocco. $(1993 ; 1994)$.

FREITAS. Maria Ester. Viver a tese é preciso! In: A bússola do escrever: desafios e es-

\footnotetext{
${ }^{13}$ Ver CAMPOS, Augusto; CAMPOS, Haroldo e PIGNATARI, Décio. Mallarmé. São Paulo: Perspectiva, 1991, p. 149-173.

${ }^{14}$ Alusão ao comentário de Marguerite Duras sobre o que é um livro. A escritora nos diz assim: "Não sei o que é um livro. Ninguém o sabe. Mas sabemos quando encontramos um. E quando não há nada sabemo-lo como sabemos que existimos, que ainda não morremos." Ver DURAS, Marguerite. Escrever. Trad. de Rubens Figueredo. São Paulo: Ed. Rocco. (1993;1994), p. 36.
} 
tratégias na orientação e escrita de teses e dissertações. BIANCHETTI, Lucídio e MACHADO, Ana Maria Netto. (Org.) São Paulo: Cortez, 2012. p. 215-226.

KERN, Keila. Marcel Broodthaers - Museu de Arte Moderna Departamento das Águias. Tese de doutorado. ECA/USP, 2015. Disponível em http://www.teses.usp.br/teses/ disponiveis/27/27159/tde-16102014-094023/pt-br.php

SIMONDON, Gilbert. El modo de existencia de los objectos tecnicos. Buenos Aires, Prometeo, 2007.

SNAUWAERT, Dirk. Marcel Broodthaers. Musée d'Art Moderne, Département des Aigles, Section des Figures, 1972. The artist as curator. MOUSSE 46 Issue \#5. 